\title{
On Comparative Analysis of Measure of Indifference of Process Parameters in Minimizing Surface Roughness of Drilling Mild Steel, Stainless Steel and Brass
}

\author{
Raimi Oluwole Abiodun ${ }^{1}$, Tanimola Babatunde Adedoyin ${ }^{2}$ \\ ${ }^{1}$ Department of Mechanical Engineering, Federal University of Technology, Akure, Nigeria \\ ${ }^{2}$ Mechanical Engineering Department, Rufus Giwa Polytechnic, Owo, Nigeria \\ Email address: \\ abiodunscholar2015@gmail.com (R. O. Abiodun), tundetanimola@yahoo.co.uk (T. B. Adedoyin) \\ To cite this article: \\ Raimi Oluwole Abiodun, Tanimola Babatunde Adedoyin. On Comparative Analysis of Measure of Indifference of Process Parameters in \\ Minimizing Surface Roughness of Drilling Mild Steel, Stainless Steel and Brass. American Journal of Engineering and Technology \\ Management. Vol. 2, No. 6, 2017, pp. 83-86. doi: 10.11648/j.ajetm.20170206.12
}

Received: October 8, 2017; Accepted: October 18, 2017; Published: November 20, 2017

\begin{abstract}
The use of optimal parameter values in an experimental investigation for minimizing surface roughness has always been the design trend of many machining operation without checking the variation levels of the process parameters if it has any measure of significant difference or not in minimizing surface roughness of the workpiece. The study carried out a comparative analysis between low, intermediate and high level of cutting speed, feed, depth of cut and tool on mild steel, stainless steel and brass using one-way ANOVA approach with the aid of statistical package for social sciences (SPSS), version 17 based on drilling operation. The findings revealed that there were no statistically significant differences between the levels for the respective workpiece in minimizing surface roughness. The result implies that the low, intermediate and high level plays equal contributing effect in minimizing surface roughness in drilling mild steel, stainless steel and brass. The study concludes that preference should not only be given to a particular level in an experimental investigation because minimum surface roughness can be achieved at any level which we might least expected.
\end{abstract}

Keywords: Indifference, Process Parameters, Minimizing, Surface Roughness, Drilling

\section{Introduction}

The process of setting an optimal condition using some selected process parameters during machining has been the scope of many research studies in machining operations [1-5]. Before setting up an optimal condition, most of this research study fails to check for variation of the measure of significant between the levels of the considered process parameters so as to know if there are significant difference or not or if a particular level has an advantage over the others in minimizing surface roughness rather than the chosen optimal value. In optimizing process parameter such as cutting speed, feed and drill diameter, [6] applied Taguchi method to obtain minimum surface roughness on the experiment performed on cast iron and ANOVA was employed to determine the most significant factors affecting the surface roughness. After the nine experimental trials in the investigation, it was found that the drill diameter was the most significant factor for the surface roughness. In the optimization of drilling process parameters of Aluminium alloy 7075, [7] employed analysis of variance to determine the most significant control factors affecting surface roughness and material removal rate. The results revealed that the depth of cut has significant role to play in producing higher material removal rate and cutting speed has significant role to play for producing lower surface roughness. In the investigation analysis of jute-flax hybrid composite for surface roughness and material removal rate using optimized process parameters, [8] employed analysis of variance to find the significance of individual parameters. The results revealed that spindle speed and drill bit diameter have most effect on material removal rate and surface roughness followed by feed rate. However, there 
has not been studies that has verify if process parameters levels has any contributing effect in minimizing surface roughness in drilling any of the three considered workpiece. It is against this background the comparative analysis of this present study seeks to investigate.

\section{Methodology}

The workpiece used in the study are En8 mild steel, SS304 stainless steel and MS58 brass of dimension $200 \mathrm{~mm}$ by 80 $\mathrm{mm}$ with a thickness of $1.5 \mathrm{~mm}$. Vertical pillar drilling machine (METALIK PK203 model) with a speed range of $75 \mathrm{rpm}$ to $3200 \mathrm{rpm}$ and driven by a motor of $1.5 \mathrm{~kW}$ was used for the machining using High Speed Steel (HSS) cutting tool. The experimental investigation of each of the workpiece was conducted twenty seven (27) times based on nine (9) runs at each level. The levels comprises of low (1400 rpm, $0.11 \mathrm{~mm} / \mathrm{rev}, 0.25 \mathrm{~mm} \& 6 \mathrm{~mm})$, intermediate (1500 rpm, $0.18 \mathrm{~mm} / \mathrm{rev}, 0.50 \mathrm{~mm} \& 8 \mathrm{~mm})$ and high $(1700$ $\mathrm{rpm}, 0.75 \mathrm{~mm} / \mathrm{rev}, 0.75 \mathrm{~mm} \& 10 \mathrm{~mm}$ ) level of cutting speed, feed, depth of cut and drill diameter. A coupling ultrasonic thickness meter (TM-8810 Model) was used to measure the surface roughness values of the selected workpiece of the drilled holes as shown on Table 1. The comparative analysis of the experimental data of the selected workpiece was done using one-way ANOVA and Tukey Post Hoc test method with the aid of statistical package for social sciences (SPSS) version 17.0 as shown on Table 2-10.

\section{Results and Discussions}

Table 1. Surface roughness values of the work-piece.

\begin{tabular}{llll}
\hline \multirow{2}{*}{ Test No. } & \multicolumn{3}{l}{ Surface Roughness Value $(\boldsymbol{\mu m})$} \\
\cline { 2 - 4 } & Mild Steel & Stainless Steel & Brass \\
\hline 1 & 9.39 & 4.33 & 7.55 \\
2 & 5.98 & 5.04 & 8.32 \\
3 & 8.67 & 6.06 & 7.72 \\
4 & 6.01 & 6.32 & 8.57 \\
5 & 5.33 & 6.07 & 9.67 \\
6 & 4.01 & 4.02 & 5.02 \\
7 & 10.58 & 6.37 & 10.23 \\
8 & 9.51 & 3.94 & 6.11 \\
9 & 7.82 & 5.51 & 5.33 \\
10 & 5.03 & 9.18 & 8.51 \\
11 & 6.46 & 9.49 & 7.83 \\
12 & 6.85 & 8.34 & 7.15 \\
13 & 8.80 & 5.06 & 6.89 \\
14 & 10.44 & 3.73 & 7.70 \\
15 & 3.86 & 6.03 & 4.79 \\
16 & 7.48 & 5.40 & 6.00 \\
17 & 6.79 & 9.01 & 4.60 \\
18 & 3.84 & 8.63 & 4.38 \\
19 & 5.92 & 7.98 & 5.60 \\
20 & 9.71 & 7.79 & 7.60 \\
21 & 10.26 & 6.32 & 7.80 \\
22 & 5.65 & 6.33 & 9.00 \\
23 & 7.85 & 6.64 & 9.70 \\
24 & 4.00 & 3.80 & 6.10 \\
25 & 9.01 & 9.34 & 8.90 \\
26 & 5.61 & 8.65 & \\
27 & 7.53 & & \\
\hline & & 7.77 & \\
\hline
\end{tabular}

Table 2. The distribution of mild steel surface roughness value in all three levels.

\begin{tabular}{|c|c|c|c|c|c|c|c|c|}
\hline & \multirow{2}{*}{$\mathbf{N}$} & \multirow{2}{*}{ Mean } & \multirow{2}{*}{ Std. Deviation } & \multirow{2}{*}{ Std. Error } & \multicolumn{2}{|c|}{ 95\% Confidence Interval for Mean } & \multirow{2}{*}{ Minimum } & \multirow{2}{*}{ Maximum } \\
\hline & & & & & Lower Bound & Upper Bound & & \\
\hline Low & 9 & 1.9970 & 0.2576 & 0.0859 & 1.7990 & 2.1950 & 1.6154 & 2.3283 \\
\hline Intermediate & 9 & 1.7672 & 0.3639 & 0.1213 & 1.4875 & 2.0469 & 1.3507 & 2.3456 \\
\hline High & 9 & 1.9870 & 0.3053 & 0.1018 & 1.7523 & 2.2216 & 1.3455 & 2.3590 \\
\hline Total & 27 & 1.9171 & 0.3186 & 0.0613 & 1.7910 & 2.0431 & 1.3455 & 2.3590 \\
\hline
\end{tabular}

Table 3. One-way ANOVA comparing mild steel surface roughness value in all three levels.

\begin{tabular}{lllll}
\hline & Sum of Squares & df & Mean Square & F \\
\hline Between Groups & 0.3036 & 2 & 0.1518 & 1.560 \\
Within Groups & 2.3356 & 24 & 0.0973 & 0.231 \\
Total & 2.6392 & 26 & & \\
\hline
\end{tabular}

Table 4. Tukey HSD Post-Hoc for mild steel surface roughness value in all three levels.

\begin{tabular}{|c|c|c|c|c|c|c|c|}
\hline & \multirow{2}{*}{ (I) Parameters } & \multirow{2}{*}{ (J) Parameters } & \multirow{2}{*}{ Mean Difference (I-J) } & \multirow{2}{*}{ Std. Error } & \multirow{2}{*}{ Sig. } & \multicolumn{2}{|c|}{ 95\% Confidence Interval } \\
\hline & & & & & & Upper Bound & Lower Bound \\
\hline \multirow[t]{6}{*}{ Tukey HSD } & \multirow[t]{2}{*}{ Low } & Intermediate & 0.2298 & 0.1471 & 0.2809 & -0.1375 & 0.5970 \\
\hline & & High & 0.0100 & 0.1471 & 0.9975 & -0.3572 & 0.3773 \\
\hline & \multirow[t]{2}{*}{ Intermediate } & Low & -0.2298 & 0.1471 & 0.2809 & -0.5970 & 0.1375 \\
\hline & & High & -0.2198 & 0.1471 & 0.3113 & -0.5870 & 0.1475 \\
\hline & \multirow[t]{2}{*}{ High } & Low & -0.0100 & 0.1471 & 0.9975 & -0.3773 & 0.3572 \\
\hline & & Intermediate & 0.2198 & 0.1471 & 0.3113 & -0.1475 & 0.5870 \\
\hline
\end{tabular}

Table 5. The distribution of stainless steel surface roughness value in all three levels.

\begin{tabular}{|c|c|c|c|c|c|c|c|c|}
\hline & \multirow{2}{*}{$\mathbf{N}$} & \multirow{2}{*}{ Mean } & \multirow{2}{*}{ Std. Deviation } & \multirow{2}{*}{ Std. Error } & \multicolumn{2}{|c|}{ 95\% Confidence Interval for Mean } & \multirow{2}{*}{ Minimum } & \multirow{2}{*}{ Maximum } \\
\hline & & & & & Lower Bound & Upper Bound & & \\
\hline Low & 9 & 1.9385 & 0.2727 & 0.0909 & 1.7289 & 2.1481 & 1.4656 & 2.2502 \\
\hline Intermediate & 9 & 1.6496 & 0.2393 & 0.0798 & 1.4657 & 1.8335 & 1.3164 & 1.8931 \\
\hline High & 9 & 1.9346 & 0.2977 & 0.0992 & 1.7058 & 2.1635 & 1.3712 & 2.2343 \\
\hline
\end{tabular}




\begin{tabular}{|c|c|c|c|c|c|c|c|c|}
\hline & \multirow{2}{*}{$\mathbf{N}$} & \multirow{2}{*}{ Mean } & \multirow{2}{*}{ Std. Deviation } & \multirow{2}{*}{ Std. Error } & \multicolumn{2}{|c|}{ 95\% Confidence Interval for Mean } & \multirow{2}{*}{ Minimum } & \multirow{2}{*}{ Maximum } \\
\hline & & & & & Lower Bound & Upper Bound & & \\
\hline Total & 27 & 1.8409 & 0.2946 & 0.0567 & 1.7244 & 1.9574 & 1.3164 & 2.2502 \\
\hline
\end{tabular}

Table 6. One-way ANOVA comparing stainless steel surface roughness value in all three levels.

\begin{tabular}{llllll}
\hline & Sum of Squares & df & Mean Square & F & Sig. \\
\hline Between Groups & 0.4942 & 2 & 0.2471 & 3.366 & 0.051 \\
Within Groups & 1.7620 & 24 & 0.0734 & & \\
Total & 2.2561 & 26 & & & \\
\hline
\end{tabular}

Table 7. Tukey HSD Post-Hoc for stainless steel surface roughness value in all three levels.

\begin{tabular}{llllllll}
\hline & \multirow{2}{*}{ (I) Parameters } & (J) Parameters & \multirow{2}{*}{ Mean Difference (I-J) } & \multirow{2}{*}{ Std. Error } & \multirow{2}{*}{ Sig. } & \multicolumn{2}{c}{ 95\% Confidence Interval } \\
\cline { 6 - 8 } & & & & Upper Bound & Lower Bound \\
\hline Tukey HSD & Low & Intermediate & 0.2889 & 0.1277 & 0.0810 & -0.0301 & 0.6079 \\
& & High & 0.0039 & 0.1277 & 0.9995 & -0.3151 & 0.3229 \\
& Intermediate & Low & -0.2889 & 0.1277 & 0.0810 & -0.6079 & 0.0301 \\
& \multirow{2}{*}{ High } & High & -0.2850 & 0.1277 & 0.0861 & -0.6040 & 0.0340 \\
& Low & -0.0039 & 0.1277 & 0.9995 & -0.3229 & 0.3151 \\
& Intermediate & 0.2850 & 0.1277 & 0.0861 & -0.0340 & 0.6040 \\
\hline
\end{tabular}

Table 8. The distribution of brass surface roughness value in all three levels.

\begin{tabular}{|c|c|c|c|c|c|c|c|c|}
\hline & \multirow{2}{*}{$\mathbf{N}$} & \multirow[b]{2}{*}{ Mean } & \multirow{2}{*}{ Std. Deviation } & \multirow[b]{2}{*}{ Std. Error } & \multicolumn{2}{|c|}{$95 \%$ Confidence Interval for Mean } & \multirow{2}{*}{ Minimum } & \multirow[b]{2}{*}{ Maximum } \\
\hline & & & & & Lower Bound & Upper Bound & & \\
\hline Low & 9 & 2.0173 & 0.1218 & 0.0406 & 1.9236 & 2.1109 & 1.7228 & 2.1412 \\
\hline Intermediate & 9 & 1.9829 & 0.2705 & 0.0902 & 1.7750 & 2.1908 & 1.5665 & 2.2721 \\
\hline High & 9 & 1.8920 & 0.3127 & 0.1042 & 1.6516 & 2.1324 & 1.4770 & 2.3253 \\
\hline Total & 27 & 1.9641 & 0.2451 & 0.0472 & 1.8671 & 2.0610 & 1.4770 & 2.3253 \\
\hline
\end{tabular}

Table 9. One-way ANOVA comparing brass surface roughness value in all three levels.

\begin{tabular}{llllll}
\hline & Sum of Squares & df & Mean Square & F & Sig. \\
\hline Between Groups & 0.0754 & 2 & 0.0377 & 0.608 & 0.552 \\
Within Groups & 1.4865 & 24 & 0.0619 & & \\
Total & 1.5619 & 26 & & & \\
\hline
\end{tabular}

Table 10. Tukey HSD Post-Hoc for brass surface roughness value in all three levels.

\begin{tabular}{|c|c|c|c|c|c|c|c|}
\hline & \multirow{2}{*}{ (I) Parameters } & \multirow{2}{*}{ (J) Parameters } & \multirow{2}{*}{ Mean Difference (I-J) } & \multirow{2}{*}{ Std. Error } & \multirow{2}{*}{ Sig. } & \multicolumn{2}{|c|}{ 95\% Confidence Interval } \\
\hline & & & & & & Upper Bound & Lower Bound \\
\hline \multirow{6}{*}{ Tukey HSD } & \multirow[t]{2}{*}{ Low } & Intermediate & 0.0344 & 0.1173 & 0.9539 & -0.2586 & 0.3273 \\
\hline & & High & 0.1252 & 0.1173 & 0.5429 & -0.1678 & 0.4182 \\
\hline & \multirow[t]{2}{*}{ Intermediate } & Low & -0.0344 & 0.1173 & 0.9539 & -0.3273 & 0.2586 \\
\hline & & High & 0.0909 & 0.1173 & 0.7219 & -0.2021 & 0.3839 \\
\hline & \multirow[t]{2}{*}{ High } & Low & -0.1252 & 0.1173 & 0.5429 & -0.4182 & 0.1678 \\
\hline & & Intermediate & -0.0909 & 0.1173 & 0.7219 & -0.3839 & 0.2021 \\
\hline
\end{tabular}

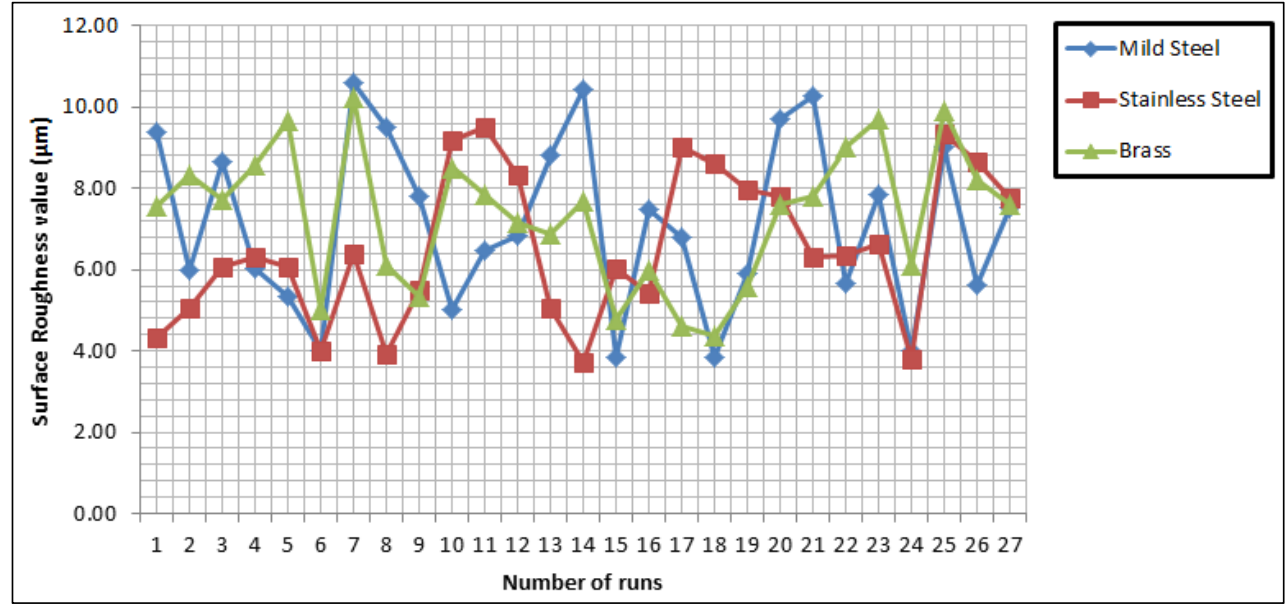

Figure 1. Graph of surface roughness value of the mild steel, stainless steel and brass. 
There were no statistically significant differences between the levels in the mild steel, stainless steel and brass as determined by one-way ANOVA which are having the following F-test result of $1.560,3.366$ and 0.608 with corresponding p-values of $0.231,0.051$ and 0.552 respectively as shown on Table 3, Table 6 and Table 9. A Tukey post hoc test for mild steel, stainless steel and brass revealed that the surface roughness after drilling was not statistically significant at the three levels considered as shown on Table 4, Table 7 and Table 10. For mild steel as in Table 2 and Table 4, the Tukey post hoc test revealed no statistically significant at low level after taking the intermediate $(1.77 \pm 0.36 \mu \mathrm{m}, \mathrm{p}=0.281)$ and high $(1.99 \pm$ $0.31 \mu \mathrm{m}, \mathrm{p}=0.997)$ level. There was also no statistically significant at intermediate level after taking the low (2.00 \pm $0.26 \mu \mathrm{m}, \mathrm{p}=0.281)$ and high $(1.99 \pm 0.31 \mu \mathrm{m}, \mathrm{p}=0.311)$ level. There was also no statistically significant at high level after taking low $(2.00 \pm 0.26 \mu \mathrm{m}, \mathrm{p}=0.997)$ and intermediate $(1.77 \pm 0.36 \mu \mathrm{m}, \mathrm{p}=0.311) \quad$ level. For stainless steel as in Table 5 and Table 7 , the Tukey post hoc test revealed no statistically significant at low level after taking the intermediate $(1.65 \pm 0.24 \mu \mathrm{m}, \mathrm{p}=0.081)$ and high $(1.93 \pm 0.30 \mu \mathrm{m}, \mathrm{p}=0.999)$ level. There was also no statistically significant at intermediate level after taking the low $(1.94 \pm 0.27 \mu \mathrm{m}, \mathrm{p}=0.081)$ and high (1.93 \pm $0.30 \mu \mathrm{m}, \mathrm{p}=0.086$ ) level. Also, there was no statistically significant at high level after taking the low (1.94 \pm $0.27 \mu \mathrm{m}, \mathrm{p}=0.999)$ and intermediate $(1.65 \pm 0.24 \mu \mathrm{m}, \mathrm{p}=$ 0.086) level. For brass as in Table 8 and Table 10, the Tukey post hoc test revealed no statistically significant at low level after taking the intermediate $(1.98 \pm 0.27 \mu \mathrm{m}, \mathrm{p}=0.954)$ and high $(1.89 \pm 0.31 \mu \mathrm{m}, \mathrm{p}=0.543)$ level. There was also no statistically significant at intermediate level after taking the low $(2.02 \pm 0.12 \mu \mathrm{m}, \mathrm{p}=0.954)$ and high $(1.89 \pm$ $0.31 \mu \mathrm{m}, \mathrm{p}=0.722$ ) level. Also, there was no statistically significant at high level after taking the low (2.02 \pm $0.12 \mu \mathrm{m}, \mathrm{p}=0.543)$ and intermediate $(1.98 \pm 0.27 \mu \mathrm{m}, \mathrm{p}=$ 0.722 ) level. In addition, the graph in Figure 1 revealed similar agreement to the comparative analysis of mild steel, stainless and brass as shown on the result tables. However, in the research study of [9], before chosen an optimal condition for surface roughness during end milling of CFRPAluminium composite laminates, the study results showed a similar measure of indifferences to our present investigation that the three levels revealed the same pattern of optimum machining parameters despite having different values of surface roughness at each levels.

\section{Conclusion and Recommendation}

The study which investigates on comparative analysis of measure of indifferences of process parameters in minimizing surface roughness in drilling mild steel, stainless steel and brass revealed that there are no significant differences between the considered levels which implies that low, intermediate and high level plays equal contributing effect in minimizing surface roughness in the machining operation of the selected workpiece. However, it is highly recommended that preference should not only be given to a particular level in an experimental investigation because minimum surface roughness can be achieved at any level which we might least expected irrespective of chosen optimal condition for an experiment.

\section{References}

[1] Kumar, P., Oberoi, J. S., Singh, C., \& Dhiman, H., (2014). Analysis and optimization of parameters affecting surface roughness in boring process. International Journal of advanced Mechanical Engineering, 4 (6), 647-655.

[2] Moghri, M., Madic, M., Omidi, M., \& Farahnakian, M., (2014). Surface roughness optimization of polyamide6/nanoclay nanocomposites using artificial neural network: genetic algorithm approach. The Scientific World Journal, Hindawi Publishing Corporation, ID 485205, 1-7.

[3] Sangwan, K. S., Saxena, S., \& Kant, G., (2015). Optimization of machining parameters to minimize surface roughness using integrated ANN-GA approach. The $22^{\text {nd }}$ CIRP Conference on Life Cycle Engineering, 305-310, available at: www.sciencedirect.com.

[4] Marimuthu, P., Kannan, T. T. M., \& Saravanan, S., (2015). Experimental investigation and design optimization of micro drilling process parameters of austenitic stainless steel (Aisi 316) sheets by doe concepts. IOSR Journal of Mechanical and Civil Engineering (IOSR-JMCE), 12 (5), 24-28, doi: $10.9790 / 1684-12552428$.

[5] Tamang, S. K., \& Chandrasekaran, M., (2015). Modelling and optimization of parameters for minimizing surface roughness and tool wear in turning $\mathrm{AL} / \mathrm{SiCp} \mathrm{MMC}$, using conventional and soft computing techniques. Advances in Production Engineering \& Management, 10 (2), 59-72, http://dx.doi.org/10.14743/apem2015.2.192.

[6] Sumesh, A. S., \& Melvin, E. S., (2016). Optimization of drilling parameters for minimum surface roughness using Taguchi method. IOSR Journal of Mechanical and Civil Engineering (IOSR-JMCE) at International Conference on Emerging Trends in Engineering \& Management (ICETEM), $12-20$.

[7] Alagarsamy, S. V., Sagayaraj, S. A. V., \& Raveedran, P., (2016). Optimization of drilling process parameters on surface roughness and material removal rate by using Taguchi method. International Journal of Engineering Research and General Science, 4 (2), 290-298.

[8] Ramnath, B. V., Sharavanan, S., \& Jeykrishnan, J., (2017). Optimization of process parameters in drilling of fibre hybrid composite using Taguchi and grey relational analysis. IOP Conf. Series: Materials Science and Engineering (183), 012003, doi:10.1088/1757-899X/183/1/012003.

[9] Nurhaniza, M., Ariffin, M. K. A. M., Mustapha, F., \& Baharudin, B. T. H. T., (2016). Analysing the effect of machining parameters setting to the surface roughness during end-milling of CFRP-Aluminium composite laminates. International Journal of Manufacturing Engineering, ID: 4680380, 1-9, available at: http://dx.doi.org/10.1165/2016/4680380. 